\title{
O Poema Pedagógico de Anton Makarenko
}

The Pedagogical Poem of Anton Makarenko

http://dx.doi.org/10.5007/2178-4582.2015v49n1p110

Gabriel Lopes Rosa Feigel

Universidade Federal de Santa Catarina, Florianópolis/SC, Brasil

\section{Resenha de:}

MAKARENKO, Anton. Poema Pedagógico. São Paulo: Editora 34, 2005. 656p.

O "Poema Pedagógico" é uma obra literária e biográfica. Foi escrito originalmente como uma trilogia pelo pedagogo ucraniano Anton Semionovich Makarenko (1888-1939), e trata do período em que ele dirigiu a Colônia Górki, uma instituição responsável pela educação, reabilitação e reintegração social de jovens soviéticos marginalizados.

Na Colônia de Trabalho Górki, centenas de meninos e meninas foram reeducados para assumir o comando de suas próprias vidas e da nova sociedade socialista soviética. Os acontecimentos narrados no livro se passam na Ucrânia entre 1920 e 1928 - período em que Anton Makarenko dirigiu a Colônia Górki - e estão enraizados nos acontecimentos políticos e culturais que se desenrolavam no contexto educacional ucraniano, numa fase importante de consolidação do socialismo na União das Repúblicas Socialistas Soviéticas.

Devido a diversos fatores decorrentes da Primeira Guerra Mundial, da guerra civil anterior e posterior à Revolução Russa e, principalmente, às precárias condições históricas da educação nos países do leste europeu, estima-se que a população soviética era constituída de algo em torno de $90 \%$ de analfabetos no período que sucedeu à Revolução de Outubro (ARANHA, 2006; BITTAR, FERREIRA JR, 2011).

Naquele contexto, as tarefas demandadas pela nova educação socialista soviética não estavam relacionadas apenas à alfabetização da sua população. Era imprescindível que a nova educação socialista instrumentalizasse a população soviética através de formação consistente, tanto teórica quanto técnica, e que essa educação tornasse os cidadãos soviéticos politicamente ativos e eticamente responsáveis pela transformação de um império moribundo semifeudal em um conjunto de modernos países industrializados essencialmente coletivistas. 
Foi nesse cenário de transformações sociais radicais que Anton Makarenko foi convidado a assumir, num pequeno sítio da província de Poltava, a direção pedagógica de uma colônia de trabalhos para delinquentes juvenis e menores abandonados, denominada posteriormente por seus membros de Colônia Górki.

Durante o tempo em que Makarenko dirigiu a Colônia de Trabalhos Górki, ela teve três sedes principais, ambas situadas em solo ucraniano: Poltava, Trepke e Kuriaj. Essas sedes representam, no livro "Poema Pedagógico", os estágios de aprofundamento e desenvolvimento dialético da concepção pedagógica do autor.

Foi em Poltava (1920-1923), que as atividades voltadas à organização global do coletivo tiveram início. Nesse período, foram estabelecidas as primeiras regras da instituição referentes à realização das tarefas numa proposta de autogestão coletiva. As tarefas eram cumpridas pelos colonistas através dos destacamentos da Colônia Górki, em que educandos, de idades variadas, se responsabilizaram de maneira organizada pela realização de atividades essenciais à sobrevivência da Colônia.

Desse modo, sentimentos como dever e honra se tornaram imprescindíveis para a responsabilização mútua pela sobrevivência do coletivo. Era necessário estudar e trabalhar com rigorosa disciplina, porém com muita alegria no hoje e otimismo no amanhã, um otimismo necessário, pois, de acordo com Makarenko , "[...] o ser humano não pode viver no mundo, se não tiver pela frente alguma coisa jubilosa" (2005, p. 569).

Desde o início do trabalho de Makarenko na Colônia Górki, os educandos deveriam estudar e trabalhar com o máximo de disciplina, mas também participar de atividades culturais e recreativas, como serões de literatura e encenação de peças teatrais. O nome da Colônia Górki, inclusive, é uma homenagem ao célebre escritor russo Alexei Maxímovich Peshkov (1868-1936), mais conhecido como Máximo Górki, ou Máximo, o Amargo.

Durante anos, Makarenko e os "gorkianos" leram e releram as obras de Máximo Górki, especialmente a sua trilogia autobiográfica - "Infância”, "Ganhando meu Pão" e "Minhas Universidades" -, em que Górki relata como foi sair de casa ainda criança para trabalhar e sobreviver pelas ruas e estradas da velha Rússia, tendo os livros como sua única arma de defesa diante das injustiças humanas que a vida lhe apresentou.

A identificação dos educandos com Máximo Górki foi natural e imediata, e seu desejo de se tornarem "gorkianos" rendeu muitos frutos positivos para a proposta pedagógica de Makarenko, pois Górki “[...] passou a ser o modelo da coragem, da dignidade, da honra, da esperança e da transformação para os 
educandos, através da sua própria história de vida e dos seus personagens" (LUEDEMANN, 2002, p. 141).

Em Trepke (1923-1926), os educandos já se responsabilizavam totalmente pela Colônia, e, além de estarem mais saudáveis, limpos e bem vestidos, também já se alimentavam em grande parte do que plantavam e colhiam, além de criarem animais e produzirem diversos produtos derivados desses trabalhos. Nessa época, iniciaram os projetos dos educandos para ingressarem na Rabfak, a faculdade operária.

Em 1924, foi enviada a primeira geração de "gorkianos" para a Rabfak, e isso resultou em preocupações constantes para Makarenko, pois partia da Colônia uma vanguarda especial de colonistas; alguns deles eram até mesmo os principais comandantes dos destacamentos, e Makarenko não sabia como os colonistas e ex-colonistas lidariam com essa nova situação. Felizmente, o coletivo da Colônia Górki logo se adaptou, e os antigos colonistas também se adaptaram muito bem à nova realidade na Rabfak.

Makarenko aprendeu muito com essa experiência e confirmou expectativas anteriores suas de que um bom núcleo se multiplicaria também pela divisão. Os "rabfakianos" enviavam cartas com muita frequência para os ex-colegas da Colônia Górki, e elas eram lidas e ouvidas atentamente pelos "gorkianos", especialmente durante as assembleias gerais, estimulando-os a estudar cada vez mais para também conseguir realizar o sonho de ingressar na faculdade operária.

Em Kuriaj (1926-1928), Makarenko teve de reiniciar o seu trabalho pedagógico praticamente do zero, exceto que agora ele tinha uma visão pedagógica muito clara do que deveria ser realizado naquele local. Antes da sua chegada e da chegada da Colônia Górki, já havia em Kuriaj uma instituição responsável pela reeducação de menores abandonados e infratores, mas esta era uma instituição aparentemente abandonada, totalmente negligenciada pelos administradores e educadores responsáveis pelo local.

Makarenko foi convidado pela Comissão de Instrução Pública da Ucrânia a assumir a direção da instituição e, em pouco tempo, algumas das principais metas da Colônia Górki - "limpeza, trabalho, estudo, vida nova, uma nova felicidade humana" (MAKARENKO, 2005, p. 472) - alcançaram êxito, embora o desafio fosse gigantesco e os esforços dele e dos "gorkianos" para superá-lo tenham sido hercúleos.

Para se ter uma ideia, ele iniciou o trabalho pedagógico em Poltava sendo responsável por apenas seis educandos; se responsabilizou em Trepke por aproximadamente cem deles, e teve de dirigir, em Kuriaj, uma colônia de trabalho, educação e reintegração social que contava com mais de quinhentos 
educandos - além de educadores e demais funcionários auxiliares dos serviços gerais da instituição.

Entretanto, para Makarenko (2005, p. 387), “[...] as formas de vida de um coletivo são o movimento para a frente e a forma de morte é a parada", tornando assim necessária a presença de desafios, por maiores que fossem, como única possibilidade de não haver estagnação e, assim, manter vivo o coletivo humano, sempre em movimento.

Quando ainda estava em Poltava, Makarenko leu muito livros sobre educação, tanto os clássicos quanto os contemporâneos, mas não encontrou respostas totalmente satisfatórias sobre como educar adequadamente crianças e jovens, a fim de torná-los os "novos homens" tão necessários à nova e revolucionária sociedade socialista soviética. Esse é um dos principais motivos que o levaram a se conformar e tentar compreender a essência de uma educação coletiva autogestionária a partir de elementos concretos da vida cotidiana, negligenciando parcialmente as fórmulas pedagógicas livrescas e as concepções pedagógicas que estavam mais em voga naquele período.

Para Makarenko, a pedagogia não deveria se preocupar apenas com o desenvolvimento das personalidades individuais de cada educando, mas sim em como desenvolver ao máximo essas personalidades singulares numa educação gestada no coletivo escolar e voltada às necessidades de outro grande coletivo, que era, neste caso, a sociedade socialista soviética.

Essa pedagogia voltada ao coletivo deveria ser uma ciência constituída de um conjunto teórico e técnico totalmente voltado às necessidades concretas da sociedade. Através da mediação de professores capacitados, a escola deveria desenvolver ao máximo os aspectos intelectuais, psicológicos, éticos e culturais de todas as crianças. Este desenvolvimento deveria ocorrer gradativamente, pois derivaria de transformações importantes nas personalidades dos educandos, e só se tornaria viável a partir da participação efetiva dos educandos na resolução de problemas diários demandados pelo coletivo escolar e no seu engajamento político real no movimento geral da sociedade.

Apesar da experiência pedagógica de Anton Makarenko ter sido considerada posteriormente como um dos atos científicos e culturais mais importantes e originais no cenário educacional do século XX (MANACORDA, 1997; CAMBI, 1999), o diretor da Colônia Górki foi perseguido constantemente por seus pares, que criticavam principalmente o método de organização dos coletivos da Colônia, muito semelhantes às organizações militares, tanto pelas severas punições aos colonistas não comprometidos com o coletivo, quanto pela organização dos destacamentos responsáveis pela realização das tarefas na colônia. 
Os destacamentos eram realmente muito semelhantes a verdadeiras tropas militares, pois havia treinos físicos rigorosos e fileiras de rapazes prontos para realizar de maneira eficaz todas as tarefas diárias demandadas pelo coletivo. Quanto às punições severas, elas estavam mais relacionadas à expulsão de colonistas do que propriamente à aplicação de castigos físicos, embora no início do trabalho em Poltava, Makarenko tenha de fato agredido fisicamente um colonista e, em outro contexto posterior, ele tenha dito que não saberia educar sem punições e que seria preciso que alguém lhe ensine "esta arte" (MAKARENKO, 2005, p. 369).

Depois de passar muitos anos se desgastando com a burocracia estatal e com a perseguição implacável de alguns técnicos e especialistas em educação, Makarenko passou a repensar a ideia de dirigir apenas colônias infantis e passou a demonstrar interesse em novos projetos educacionais que propusessem a criação de novas experiências educacionais de coletivos autogeridos.

No final do ano de 1927, ele recebeu um convite para dirigir a Colônia Dzerjinski, uma instituição que ainda estava em fase de construção e prometia bem mais autonomia e menos burocracia para o seu trabalho pedagógico em comparação com o que ele encontrava cotidianamente na Colônia Górki.

A princípio, ele aceitou a oferta, desde que pudesse dirigir simultaneamente a Colônia Dzerjinski e a Colônia Górki. Mas, em 1928, após ter sido julgado por seus pares e ter sido acusado injustamente de utilizar um sistema educacional não soviético, Makarenko optou por se demitir do cargo de diretor da Colônia Górki.

Ele aguardou para anunciar a sua despedida somente depois da grande celebração referente à primeira e única visita do célebre escritor Máximo Górki à Colônia Górki, ocorrida em meados de 1928. Após a partida do escritor, Makarenko anunciou a alguns amigos e educadores que, infelizmente, a partir daquele momento, ele estaria de partida para sempre da Colônia.

Os "gorkianos" perdiam, assim, o seu amado diretor, mas, de acordo com Makarenko, o coletivo da Colônia Górki se recusou a morrer, e os "gorkianos" cresceram e espalharam suas ricas experiências coletivistas por toda a extensão do gigantesco solo soviético.

Em suma, o "Poema Pedagógico" apresenta uma autobiografia típica da literatura russa: parecido com um romance, o livro contém uma narrativa instigante numa linguagem muito fluente, além de apresentar belíssimas descrições de eventos, cenários e profundas caracterizações das personagens. Entretanto, o que torna esse livro particularmente interessante são as diversas descrições de passagens reais em que ocorrem aprendizados im- 
portantes de Makarenko e dos "gorkianos" sobre o valor da educação e do trabalho em função de um coletivo autogerido.

A edição do "Poema Pedagógico" lançada em 2005 pela Editora 34 reúne a trilogia original de Anton Makarenko em um único livro de 656 páginas, com tradução de Tatiana Belinsky e pósfácio de Zóia Prestes. Como bem destaca Prestes no posfácio deste livro, embora os problemas sociais e educacionais enfrentados por Makarenko se relacionem a um país em um período muito diferente do nosso, o livro permanece surpreendentemente atual. Recomendamos a leitura do "Poema Pedagógico", especialmente a educadores de um modo geral e também às demais pessoas interessadas em história da educação e da cultura no alvorecer da revolucionária URSS.

\section{Referências}

ARANHA, Maria Lucia de Arruda. História da educação e da pedagogia: geral e Brasil. São Paulo: Moderna, 2006. 384p.

CAMBI, Franco. História da pedagogia. São Paulo: Ed. UNESP, 1999. 701p.

LUEDEMANN, Cecília da Silveira. Anton Makarenko: vida e obra - a pedagogia na revolução. São Paulo: Expressão Popular, 2002. 432p.

MANACORDA, Mario Alighiero. História da educação: da antiguidade aos nossos dias. São Paulo: Cortez, 1997. 382p.

BITTAR, Marisa; FERREIRA JR., Amarilio. A educação na Rússia de Lênin. Revista HISTEDBR On-line, Campinas, v. 11, n. 41e, p. 377-396, abr. 2011. Disponível em: http://www. fae.unicamp.br/revista/index.php/histedbr/article/view/3293/2919>. Acesso em: 20 jan. 2013.

Submissão em: 29/01/2013

Revisão em: 29/07/2013

Aceite em: 13/08/2013

Gabriel Lopes Rosa Feigel é graduado em Psicologia pela UFSC, possui formação em Orientação Profissional pelo Instituto do Ser de Florianópolis e especialização em Psicologia Clínica pela Uniara, São Paulo. Desde 2013 atua como psicólogo escolar no Sistema de Ensino Energia, em Florianópolis, onde trabalha com adolescentes e jovens em busca de aprovação no vestibular. Endereço para correspondência: Rua Saldanha Marinho n ${ }^{\circ}$ 51, Centro, Florianópolis, Santa Catarina. CEP 88010-450 E-mail: gabriel.feigel@gmail.com 